\title{
A PRODUÇÃO CIENTÍFICA EM EDUCAÇÃO FÍSICA DE 2001 A 2010: CAMINHOS DA CONSTRUÇÃO DE UM CAMPO
}

\author{
SCIENTIFIC PRODUCTION IN PHYSICAL EDUCATION FROM 2001 TO 2010: \\ THE CONSTRUCTION OF A FIELD
}

\section{LA PRODUCCIÓN CIENTÍFICA EN EDUCACIÓN FÍSICA DE 2001 A 2010: CAMINOS DE LA CONSTRUCCIÓN DE UN CAMPO}

\section{Pedro Henrique Zubcich Caiado de Castro*, Alan Camargo Silva**, Luis Aureliano Imbiriba Silva**, Sílvia Maria Agatti Lüdorf**}

\begin{abstract}
Palavras chave: Educação Física. Programas de pós-graduação. Atividades científicas e tecnológicas.

Resumo: Este estudo objetivou compreender a produção de programas de pósgraduação stricto sensu em Educação Física, no período de 2001 a 2010, tendo como pano de fundo as "regras do jogo científico" vigentes no campo. Foram selecionados 1.398 trabalhos, entre dissertações e teses, dos programas de pós-graduação: USP, UNESP, UFRGS, UNICAMP e UGF. A análise dos dados foi realizada a partir dos enfoques temáticos: biodinâmico, sociocultural e pedagógico. Os resultados revelaram a predominância do viés biodinâmico, cuja concentração de estudos reside, principalmente, nos programas da USP, UNESP e UFRGS. Já a temática sociocultural foi identificada com maior incidência na UNICAMP e UGF. $O$ enfoque pedagógico foi encontrado em menor proporção em todos os programas. Uma análise a partir de Pierre Bourdieu apontou que a política da pósgraduação da Área 21, referendada e incentivada pela Capes, e seus impactos no campo têm favorecido essa construção do campo científico da Educação Física.
\end{abstract}

Keywords: Physical education Graduate studies programs. Scientific and technical activities.
Abstract: This study aimed to analyze the scientific production of regular-length graduate programs in Physical Education from 2001 to 2010. Its background included the "scientific game rules" in the field. A total of 1,398 works were selected from the following programs: USP, UNESP, UFRGS, UNICAMP and UGF, including master's dissertations and PhD theses. Data analysis used thematic approaches: biodynamic, sociocultural and pedagogical. The results showed the prevalence of the biodynamic approach concentrated mainly at USP, UNESP and UFRGS. Sociocultural themes, in turn, were found to have higher incidence at UNICAMP and UGF. The pedagogical approach was found in lower proportion in all programs. Considering Pierre Bourdieu's theoretical perspective, it is possible to argue that postgraduate scientific rules of Area 21, supported and encouraged by CAPES and its impacts on the field have been promoting this construction of the scientific field of Physical Education.
Palabras clave: Educación Física. Programas de postgrado. Actividades científicas y tecnológicas.
Resumen: Este estudio pretende comprender la producción de programas de postgrado stricto sensu en Educación Física, durante el período de 2001 a 2010, teniendo como telón de fondo las "reglas del juego científico" vigentes en este campo. Fueron seleccionados 1.398 trabajos, entre disertaciones y tesis, de los programas de postgrado de: USP, UNESP, UNICAMP, UFRGS y UGF. El análisis de los datos se realizó a partir de los enfoques temáticos: biodinámico, sociocultural y pedagógico. Los resultados revelaron el predominio del enfoque biodinámico, cuya concentración de estudios reside principalmente en los programas de: USP, UNESP y UFRGS. Ya el enfoque sociocultural se ha identificado con mayor incidencia en: UNICAMP y UGF. El enfoque pedagógico se ha encontrado en menor proporción en todos los programas. Un análisis a partir de Pierre Bourdieu muestra que la política de postgrado del Area 21, apoyada e impulsada por la CAPES, así como sus impactos en el campo, ha favorecido esta construcción del campo científico de la Educación Física.
*Faculdades São José. Rio de Janeiro, RJ, Brasil.

E-mail: zubufrj@ hotmail.com

**Universidade Federal do Rio de Janeiro. Rio de Janeiro, RJ, Brasil. E-mail: alan10@zipmail.com.br; aurelio@eefd.ufrj.br; sagatti.rlk@terra.com.br

Recebido em: 09-05-2016 Aprovado em: 22-05-2017

(c) (1) (8) Licence 


\section{INTRODUÇÃO}

O surgimento das primeiras Escolas de Educação Física no Brasil, entre o final do século XIX e início do século XX, foi marcado por um contexto político-cultural permeado pelos discursos higienista ${ }^{1}$ e militarista ${ }^{2}$. Tais influências tiveram papel significativo na constituição da base epistemológica da Educação Física ${ }^{3}$, com aproximação do referencial teórico e metodológico das Ciências Naturais (SOARES, 2003; VELOZO, 2010). Entretanto, a década de 1980 foi caracterizada pela ampliação do seu repertório de conhecimentos, principalmente aquele atrelado às Ciências Humanas e Sociais (SOUZA; SILVA, 1997; SÁNCHEZ GAMBOA, 2007).

Neste contexto, compreende-se que a aproximação da Educação Física com diferentes domínios do conhecimento propiciou a conformação de um campo científico caracterizado pela multiplicidade teórico-epistemológica, tendo em vista as pesquisas abarcadas pela área com distintos enfoques temáticos (DAOLIO, 2007; SÁNCHEZ GAMBOA, 2007).

Dentre as entidades produtoras de conhecimento científico da área, destacam-se os Programas de Pós-Graduação Stricto Sensu em Educação Física (PPGEF). É neste espaço, majoritariamente, que 0 debate acerca do referencial epistemológico da Educação Física se estabelece, principalmente, no final da década de 1990 (DACOSTA; DUARTE, 2003; RESENDE; VOTRE, 2003).

O cenário acadêmico recente apresenta significativo crescimento do número de PPGEF (ROSA; LETA, 2011). De acordo com as informações fornecidas pela Coordenação de Aperfeiçoamento de Pessoal de Nível Superior (Capes) ${ }^{4}$ quanto aos cursos recomendados ${ }^{5}$, na década de 1990 havia cerca de nove programas reconhecidos pela entidade, entretanto, a partir dos anos 2000, tal número recrudesceu para, no início de 2017, 37 PPGEF. Denota-se então um recorte temporal de intenso crescimento e, consequentemente, revelador quanto ao desenvolvimento acadêmico-científico da Educação Física, no novo milênio - principalmente no que tange aos PPGEF.

Tendo como pano de fundo a noção de campo científico de Bourdieu (1983a; 1983b; 2004), autor fulcral para discussões do presente artigo, considera-se a Educação Física enquanto campo de investigações científicas. Para Bourdieu (1983a; 1983b; 2004), o campo científico é um espaço social de relações objetivas dotado de lógica própria, embora sujeito a influências externas, representado como locus de disputa entre cientistas, que, por sua vez, têm suas posições definidas no campo pelo acúmulo de capital científico que possuem perante seus pares.

A relação de força entre esses agentes é demarcada pelas tensões na tentativa de definição das regras de produção científica e a posição de domínio daqueles que compõem a área. No que tange à especificidade do campo da Educação Física, observa-se, em virtude de suas variadas possibilidades temáticas de estudos, 0 acirramento das disputas pela definição de regras científicas mais propícias a uma ou outra vertente epistemológica (LAZZAROTTI

1 Movimento que preconizava a promoção da saúde e dos hábitos higiênicos através do exercício físico (MENDES; NÓBREGA, 2008). 2 Movimento militarista que marcou a formação da Educação Física brasileira pela sistematização de exercícios físicos, oriundos da prática militar, legitimados pelo discurso médico (SOARES, 2003).

3 Consideramos bases epistemológicas da Educação Física como "pressupostos teórico-filosóficos presentes nos diferentes projetos de delimitação da Educação Física como um possível campo acadêmico-científico [...] os fundamentos teóricos balizadores dos distintos discursos da Educação Física [...] como interrogação constante dos saberes constituídos" (SÁNCHEZ GAMBOA, 2007, p. 15).

4 A Capes é uma fundação do Ministério da Educação (MEC), responsável, dentre outras funções, pela regulamentação e avaliação de programas de pós-graduação stricto sensu no Brasil. Ver em: <http://www.capes.gov.br/historia-e-missao >.

5 Mais informações em: <http://www.capes.gov.br/cursos-recomendados $>$. 
FILHO et al., 2012; LAZZAROTTI FILHO; SILVA; MASCARENHAS, 2014; MAIA DA SILVA; SORIANO, 2014).

Esforços foram feitos no sentido de desvelar alguns aspectos estruturantes quanto às relações de força que conflitam no campo da Educação Física, valendo-se, também, da teoria de Pierre Bourdieu (LAZZAROTTI FILHO et al., 2012; LAZZAROTTI FILHO; SILVA; MASCARENHAS, 2014). Além destes, outras contribuições têm apresentado em seu bojo argumentativo a discussão sobre as interações entre pesquisa e regras de produção científica, pós-graduação e Educação Física (SOUZA E SILVA, 1990, 1997; LÜDORF, 2002; RESENDE; VOTRE, 2003; BETTI et al., 2004; MANOEL; CARVALHO, 2011).

Não obstante, embora haja significativo debate acerca do campo científico da área, é flagrante a lacuna de estudos quanto à investigação de dissertações e teses de PPGEF. Faz-se necessário salientar, nas palavras de Molina Neto (2006, p.153), que "As dissertações de mestrado e as teses de doutorado são o que se pode chamar de o produto mais original e demonstrativo da vitalidade, da organização e da identidade de um campo". Para Job (2006), as pesquisas realizadas em nível stricto sensu são reveladoras quanto às tendências de produção científica de uma área de conhecimento.

Com esse escopo investigativo, ressaltam-se as contribuições de Souza e Silva (1990, 1997) e Lüdorf (2002), sobre diferentes Programas de Pós-Graduação da área, no recorte temporal que compreende as décadas de 1980 e 1990. Já Souza (2011) e Santos (2012), embora tenham investigado dissertações e teses de PPGEF nos primeiros anos do século XXI, se detiveram a PPGEF específicos ou por regiões do país - o que denota uma lacuna de estudos que possam fornecer um panorama mais amplo, a partir da década de 2000.

Neste contexto, o objetivo do presente artigo foi investigar as características da produção científica do campo da Educação Física, no que tange aos enfoques temáticos presentes em dissertações e teses de PPGEF, no período 2001-2010. Pretende-se analisar, à luz de Pierre Bourdieu, as relações de força que têm conformado esse campo científico.

\section{PROCEDIMENTOS METODOLÓGICOS}

Para se chegar às dissertações e teses, primeiramente foi realizada a seleção dos PPGEF. O critério para seleção dos PPGEF baseou-se na premissa de que deveriam oferecer, ao menos, no ano de 2001, os cursos de mestrado e doutorado. A escolha por ambos os níveis da pós-graduação stricto sensu ocorreu, principalmente, pela possibilidade de verificar o estágio inicial dos estudos na área, no âmbito do mestrado, e seu aprofundamento, no doutorado, propiciando então um panorama mais abrangente.

A partir desse critério, foram selecionados cinco ${ }^{6} \mathrm{PPGEF}^{7}$, estabelecidos nas seguintes capitais do Brasil: São Paulo, Rio de Janeiro e Porto Alegre. Ao todo, o processo

6 Os PPGEF selecionados são oriundos das seguintes instituições: Universidade de São Paulo (USP), Universidade Gama Filho (UGF), Universidade Estadual de Campinas (UNICAMP), Universidade Federal do Rio Grande do Sul (UFRGS) e Universidade Estadual Paulista (UNESP).

70 curso de doutorado dos PPGEF UFRGS e UNESP, em decorrência do seu ano de início, possuem a primeira tese defendida (até onde foi possível verificar), respectivamente, nos anos 2003 e 2004. Os demais cursos de doutorado e todos os cursos de mestrado apresentam, na coleta realizada, dissertações e teses a partir de 2001. 
da coleta de dados foi realizado de 2012 até $2013^{8}$. Os anos de início dos cursos de mestrado e de doutorado são demonstrados no Quadro 1:

Quadro 1 - Início do funcionamento dos cursos nos respectivos PPGEF

\begin{tabular}{|l|c|c|c|c|c|}
\hline CURSO/ INSTITUIÇÃO & USP & UGF & UNICAMP & UFRGS & UNESP \\
\hline MESTRADO & 1977 & 1985 & 1988 & 1989 & 1991 \\
\hline DOUTORADO & 1989 & 1994 & 1993 & 1999 & 2001 \\
\hline
\end{tabular}

Fonte: Dados da Capes

Posteriormente, houve a busca das dissertações e teses desses programas, cujos resumos seriam inicialmente analisados. Nesse sentido, o site de cada programa de pósgraduação stricto sensu foi consultado e, simultaneamente, o Banco de Teses ${ }^{9}$ da Capes. Em decorrência de algumas discrepâncias detectadas no cruzamento entre os diferentes bancos de dados, recorreu-se aos coordenadores solicitando as listagens de defesa de dissertações e teses dos PPGEF selecionados, no sentido de garantir a fidedignidade da coleta. Todos os PPGEF contatados forneceram a lista requisitada.

Em posse do título das dissertações e teses, o processo de acesso aos resumos foi iniciado com base, principalmente, nos dados extraídos do Banco de Teses da Capes, por ser um repositório oficial de abrangência nacional e conter informações padronizadas. Caso a dissertação ou tese não fosse localizada nesse banco, a biblioteca digital da própria instituição era acessada. Ainda assim, quando alguns trabalhos constavam nas listagens, mas não estavam disponíveis, recorreu-se ao buscador on line Google, pelo título e/ou autor do trabalho.

Os dados principais (título, autor, orientador, resumo e link do trabalho) foram sistematizados em planilhas, por universidade e nível (mestrado ou doutorado). Os PPGEF geraram, na década analisada, o total de 1.398 trabalhos, dos quais: 1.086 dissertações de mestrado e 312 teses de doutorado.

A categorização dos trabalhos foi realizada a partir da leitura dos resumos das dissertações e teses. Se o resumo não fornecesse os insumos necessários para a análise proposta, realizavase 0 acesso ao documento na íntegra. Essa busca foi feita na biblioteca digital da instituição em análise, a qual nem sempre disponibilizava o material em seu endereço eletrônico. Nesses casos, informações como linha de pesquisa, área de concentração em que a dissertação ou tese foi desenvolvida, e ainda, currículo Lattes do autor e orientador, auxiliaram na classificação.

Buscaram-se, ainda, dados adicionais sobre os orientadores das dissertações e teses, que foram alocados, também, a partir da temática dos estudos em que apareciam - caso orientassem trabalhos em dois enfoques ou mais, contabilizou-se em cada um deles. Tal levantamento permitiu avançar na investigação também quanto ao corpo docente de cada PPGEF, para além das dissertações e teses defendidas.

A partir da Análise de Conteúdo Temático, caracterizada em Turato (2003, p. 442) por: "[...] procura nas expressões verbais ou textuais os temas gerais recorrentes que fazem a sua aparição no interior de vários conteúdos mais concretos [...]", os trabalhos foram classificados

8 À época, o PPGEF da UGF estava em funcionamento e figurava entre os mais significativos da área, no Brasil. Seu fechamento, assim como 0 de toda a UGF, ocorreu em 2014 - posterior à realização da pesquisa. 
conforme o enfoque temático, com base em Manoel e Carvalho (2011). Os estudos poderiam se situar em três categorias ${ }^{10}$ :

1. Biodinâmica: atrelados à matriz biológica, como: biomecânica, fisiologia do exercício, aprendizagem e desenvolvimento motor, nutrição esportiva, treinamento físico e desportivo e psicologia do esporte com vistas ao rendimento.

2. Sociocultural: objetivam investigar temas como o esporte e as práticas corporais nas perspectivas da Sociologia, Antropologia, História e Filosofia.

3. Pedagógica: tratam de aspectos metodológicos, sociais, políticos e filosóficos ligados à Educação Física Escolar, formação de professores e pedagogia do esporte.

Salienta-se que o processo referente à classificação dos enfoques temáticos, ainda que simplificado nessas três categorias, mostrou-se complexo, pelo nível de ambiguidade e possibilidade de categorizar alguns trabalhos em um ou mais enfoques temáticos. Nesses casos, recorria-se ao objetivo principal da dissertação ou tese, assim como ao trabalho na íntegra, para classificá-lo em uma das categorias.

\section{RESULTADOS E DISCUSSÃO}

Os resultados serão apresentados, inicialmente, em uma perspectiva geral - desvelando os achados da pesquisa sobre os PPGEF investigados. Após, serão destacadas as nuances encontradas nos programas analisados e, posteriormente, será empreendida a interpretação dos dados obtidos, a partir da literatura revista e da teoria de Bourdieu (1983a; 1983b; 2004).

A Tabela 1 apresenta um panorama geral acerca do resultado obtido de acordo com os enfoques temáticos classificados nas dissertações e teses.

Tabela 1 - Percentual e número absoluto de dissertações e teses por PPGEF no período de 2001 a 2010, por enfoque temático

\begin{tabular}{|c|c|c|c|c|c|c|c|c|c|c|}
\hline \multirow[b]{2}{*}{ Nível/PPGEF } & \multicolumn{2}{|c|}{ Biodinâmica } & \multicolumn{2}{|c|}{ Sociocultural } & \multicolumn{2}{|c|}{ Pedagógica } & \multicolumn{2}{|c|}{ Outras } & \multicolumn{2}{|c|}{ Total } \\
\hline & $\mathbf{M}$ & D & $\mathrm{M}$ & D & $M$ & D & M & D & M & D \\
\hline USP & $\begin{array}{c}78,1 \% \\
(161)\end{array}$ & $\begin{array}{c}91,5 \% \\
(54)\end{array}$ & $\begin{array}{c}11,2 \% \\
(23)\end{array}$ & $\begin{array}{c}3,4 \% \\
\text { (2) }\end{array}$ & $\begin{array}{c}9,7 \% \\
(20)\end{array}$ & $\begin{array}{c}1,7 \% \\
\text { (1) }\end{array}$ & $\begin{array}{l}1 \% \\
\text { (2) }\end{array}$ & $\begin{array}{c}3,4 \% \\
\text { (2) }\end{array}$ & $\begin{array}{l}100 \% \\
(206)\end{array}$ & $\begin{array}{c}100 \% \\
(59)\end{array}$ \\
\hline UGF & $\begin{array}{c}26,7 \% \\
(44)\end{array}$ & $\begin{array}{c}26,1 \% \\
(17)\end{array}$ & $\begin{array}{c}52,1 \% \\
(86)\end{array}$ & $\begin{array}{c}66,2 \% \\
(43)\end{array}$ & $\begin{array}{l}17 \% \\
\text { (28) }\end{array}$ & $\begin{array}{c}4,6 \% \\
(3)\end{array}$ & $\begin{array}{c}4,2 \% \\
(7)\end{array}$ & $\begin{array}{c}3,1 \% \\
(2)\end{array}$ & & $\begin{array}{c}100 \% \\
(65)\end{array}$ \\
\hline UNESP & $\begin{array}{c}61,7 \% \\
(172) \\
\end{array}$ & $\begin{array}{c}97,9 \% \\
(46) \\
\end{array}$ & $\begin{array}{c}19,7 \% \\
(55) \\
\end{array}$ & $\begin{array}{c}2,1 \% \\
\text { (1) } \\
\end{array}$ & $\begin{array}{c}17,2 \% \\
(48) \\
\end{array}$ & 0 & $\begin{array}{c}1,4 \% \\
(4) \\
\end{array}$ & 0 & $\begin{array}{l}100 \% \\
(279) \\
\end{array}$ & $\begin{array}{c}100 \% \\
(47) \\
\end{array}$ \\
\hline UFRGS & $\begin{array}{c}64,8 \% \\
(140)\end{array}$ & $\begin{array}{c}69,3 \% \\
(27)\end{array}$ & $\begin{array}{c}21,8 \% \\
(47)\end{array}$ & $\begin{array}{c}12,8 \% \\
\text { (5) }\end{array}$ & $\begin{array}{c}11,6 \% \\
(25)\end{array}$ & $\begin{array}{c}12,8 \% \\
\text { (5) }\end{array}$ & $\begin{array}{c}1,8 \% \\
(4)\end{array}$ & $\begin{array}{c}5,1 \% \\
(2)\end{array}$ & $\begin{array}{l}100 \% \\
(216)\end{array}$ & $\begin{array}{c}100 \% \\
(39) \\
\end{array}$ \\
\hline UNICAMP & $\begin{array}{c}45,9 \% \\
(101) \\
\end{array}$ & $\begin{array}{c}30,4 \% \\
(31)\end{array}$ & $\begin{array}{c}25,9 \% \\
(57) \\
\end{array}$ & $\begin{array}{c}35,3 \% \\
(36) \\
\end{array}$ & $\begin{array}{c}23,2 \% \\
(51) \\
\end{array}$ & $\begin{array}{c}28,4 \% \\
(29) \\
\end{array}$ & $\begin{array}{l}5 \% \\
(11) \\
\end{array}$ & $\begin{array}{c}5,9 \% \\
(6)\end{array}$ & $\begin{array}{l}100 \% \\
(220) \\
\end{array}$ & $\begin{array}{l}100 \% \\
(102) \\
\end{array}$ \\
\hline TOTAL & $\begin{array}{c}56,9 \% \\
(618)\end{array}$ & $\begin{array}{c}56,1 \% \\
(175)\end{array}$ & $\begin{array}{c}24,7 \% \\
(268)\end{array}$ & $\begin{array}{c}27,9 \% \\
(87)\end{array}$ & $\begin{array}{c}15,8 \% \\
(172)\end{array}$ & $\begin{array}{c}12,2 \% \\
(38)\end{array}$ & $\begin{array}{c}2,6 \% \\
(28)\end{array}$ & $\begin{array}{c}3,8 \% \\
\text { (12) }\end{array}$ & $\begin{array}{c}100 \% \\
(1086)\end{array}$ & $\begin{array}{l}100 \% \\
(312)\end{array}$ \\
\hline
\end{tabular}

Fonte: dados originais da pesquisa

A superioridade percentual do enfoque temático biodinâmico, que, por sua vez, vinculase às Ciências Naturais na Educação Física, encontra ressonância nos estudos, em menor ou

10 Além das três subdivisões conceituais propostas pelos autores, acrescentamos a categoria outros, para abarcar os estudos que não puderam ser analisados no banco de teses da Capes, nem no banco de teses da própria instituição. 
maior medida, desde as décadas de 1980 e 1990 (SOUZA E SILVA, 1990, 1997; LÜDORF, 2002). Portanto, observa-se que há trinta anos de predominância de estudos atrelados a este viés, na Educação Física.

Corroborando os dados apresentados no documento elaborado pelo Fórum de Pesquisadores das Subáreas Sociocultural e Pedagógica (CENÁRIOS..., 2015) ${ }^{11}$, os enfoques temáticos sociocultural e o pedagógico, atrelados às Ciências Humanas e Sociais, ocupam a segunda e a terceira posição, em relação ao número total de trabalhos. Um aspecto importante a ser levantado é a inferioridade quantitativa - tanto no mestrado, quanto no doutorado - em todos os PPGEF, de pesquisas com enfoque temático pedagógico.

Além disso, a Figura 1 aponta o panorama temático de cada PPGEF, a partir da soma das dissertações e teses dos níveis de mestrado e doutorado.

Figura 1 - Percentual da distribuição dos enfoques temáticos nas dissertações e teses por PPGEF - período de 2001 a 2010

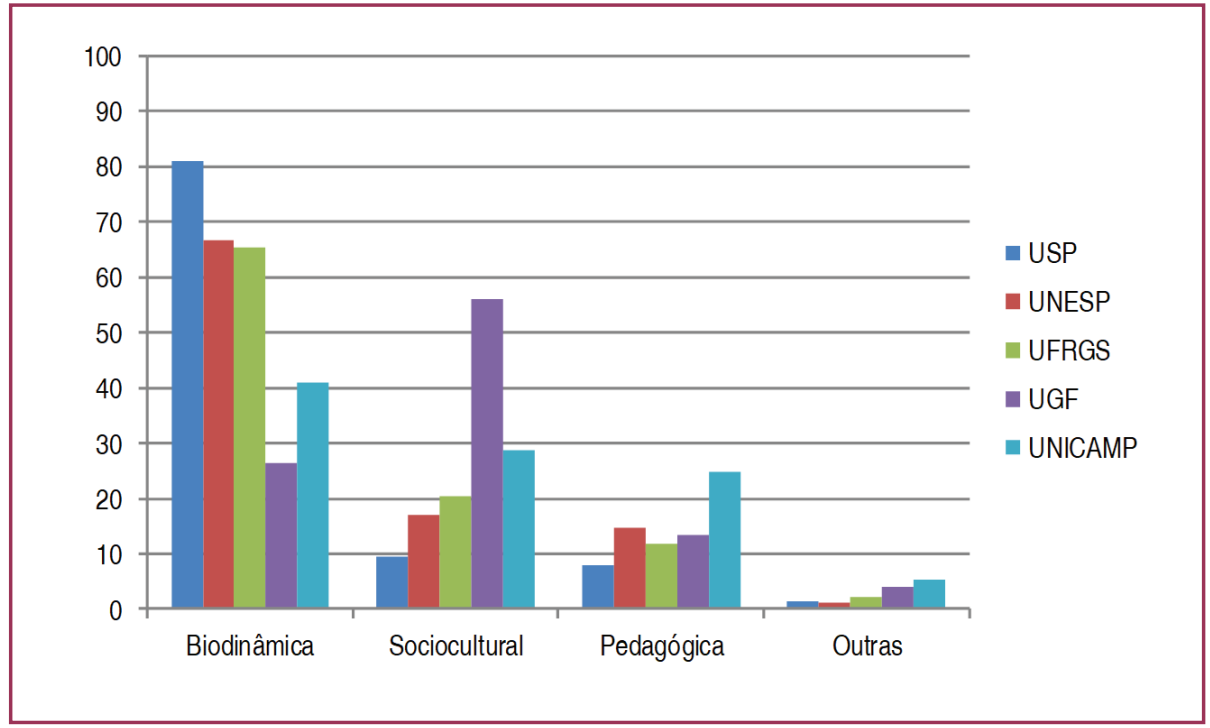

Fonte: dados originais da pesquisa

Entretanto, os dados demonstram que a superioridade do enfoque biodinâmico deve ser analisada com cautela. Observa-se que, embora preponderante nos PPGEF USP, UNESP e UFRGS, o mesmo padrão não se repete nos demais. Ao contrário, a soma dos enfoques temáticos sociocultural e pedagógico se sobrepõe ao biodinâmico na UGF e UNICAMP. Nesta perspectiva, o discurso homogeneizado acerca da supremacia biodinâmica no campo da Educação Física não pode ser considerado como algo comum a todos os PPGEF, mas sim, característico de determinados PPGEF, ao menos nos programas investigados.-

Cabe destacar que os programas USP e UNESP, caracterizados pela produção de dissertações e teses na temática biodinâmica, chegaram ao percentual, respectivamente, de $91,5 \%$ e $97,9 \%$ de trabalhos no nível de doutorado categorizados nesse enfoque temático. Pode-se depreender que os doutores, nestes PPGEF, têm sido formados basicamente na vertente biológica da EF.

Como possível consequência, baseado em Bourdieu (2004) e na importância da USP e UNESP no cenário da Educação Física brasileira - os PPGEF que mantiveram maior conceito nas regras de avaliação científica da área. Mais informações em: <http://www.cbce.org.br/noticias-detalhe.php?id=1074>. 
na avaliação Capes: notas 7 e 6, respectivamente -, aponta-se para uma perspectiva na qual as regras de avaliação científica da área tendem a ser reproduzidas. Afinal, "[...] podese genericamente verificar que quanto mais as pessoas ocupam uma posição favorecida na estrutura, mais elas tendem a conservar ao mesmo tempo a estrutura e sua posição [...]" (BOURDIEU, 2004, p. 29).

Em um outro ponto de vista, a Figura 2 mostra a evolução quantitativa, em números absolutos, das dissertações e teses categorizadas por enfoques temáticos, além do número total de trabalhos em todos os programas, no recorte do período em questão.

Figura 2 - Evolução quantitativa, ano a ano, dos trabalhos categorizados nos enfoques temáticos biodinâmico, sociocultural e pedagógico

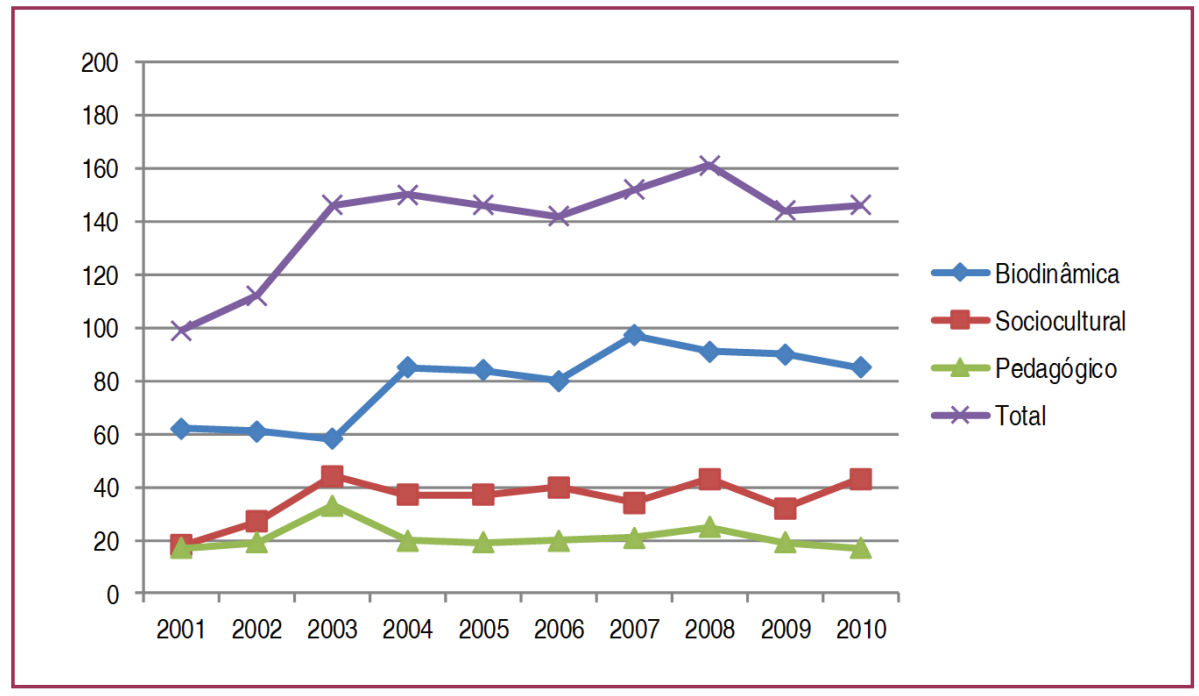

Fonte: dados originais da pesquisa

Embora oscile, acompanhando o quantitativo total de trabalhos, as dissertações e teses no enfoque temático biodinâmico - se comparados os anos de 2001 e 2010 - aumentaram aproximadamente $33 \%$. Em 2008, o aumento chega a quase $66 \%$, comparado ao ano de 2001. Nesse sentido, a evolução, em números absolutos, das dissertações e teses no enfoque biodinâmico denota considerável aumento se comparado o ano de 2001 com o ano de 2010.

Diferentemente da evolução quantitativa dos trabalhos com enfoque biodinâmico, os estudos alocados na temática sociocultural aumentaram 138\%, embora, em números absolutos, tenham se mantido consideravelmente inferiores ao primeiro. Já os trabalhos categorizados na vertente pedagógica mantiveram o mesmo quantitativo, passados dez anos, se comparados os trabalhos categorizados neste enfoque no ano de 2001 e em 2010. Ademais, é imperativo ressaltar que os estudos biodinâmicos constituem o dobro daqueles da vertente sociocultural e, ainda, o quádruplo em relação àqueles categorizados no viés pedagógico.

Os achados podem ser interpretados a partir da análise de regras de constituição científica da Educação Física. Estas, sob grande influência, mas não somente, das políticas de gestão empreendidas pela Capes e, embora haja autonomia relativa de cada campo científico quanto à resistência a influências e pressões ulteriores, também não escapam às relações de forças produzidas por agentes externos e a outros campos, como, por exemplo, a política (BOURDIEU, 1983a; 2004). 
Uma breve retomada histórica revela que, nas décadas de 1990 e 2000, a Capes passa a regulamentar mais incisivamente não só a área, mas, também, todos os programas de pósgraduação stricto sensu do Brasil, estabelecendo normas de regulamentação para os PPGEF - locus primordial para o desenvolvimento científico da área. Dentre as principais diretrizes estavam: 0 aumento quantitativo da publicação veiculada no formato de artigo; a publicação em periódicos internacionais; e a parceria intercambial com instituições de outros países (TANI, 2000; KOKUBUN, 2003).

Tais normas foram forjadas com base nos pressupostos teórico-metodológicos das Ciências Naturais e Biológicas, como a universalização e a reprodutibilidade, o que propiciou, como consequência, formas de produção de conhecimento científico mais afeitas ao enfoque temático biodinâmico dentro do campo da Educação Física (MANOEL; CARVALHO, 2011; LAZZAROTTI FILHO; SILVA; MASCARENHAS, 2014; MAIA DA SILVA; SORIANO, 2014).

Os dados empíricos desta investigação evidenciaram a eficácia no sentido de moldar o campo da Educação Física em torno de sua vertente biológica. Em 2001, momento no qual as regras avaliativas da Capes passaram a nortear de forma mais expressiva a produção científica dos programas de pós-graduação no Brasil, o quantitativo de dissertações e teses cuja temática fosse biodinâmica era composto por 99 trabalhos, número que, após uma década, aumentou para 146, chegando a 161 trabalhos em 2008.

Nesta perspectiva, a Capes é situada, nos termos de Bourdieu (2004), enquanto "estrutura estruturante", moldando as relações objetivas sobre "o que vale e o que não vale no jogo da produção científica" no campo da Educação Física. Os dominantes - agentes/ pesquisadores mais bem posicionados na estrutura e que influem na conservação do campo da Educação Física - não assumem posições prestigiosas em entidades regulamentadoras ao acaso. A posição é conquistada através do acúmulo de capital científico temporal ou institucionalizado, aquele que é, primordialmente, construído na relação política dos ocupantes de cargos de chefia de programas de pós-graduação, coordenação de agências de fomento, chefes de laboratório e presidentes de entidades científicas (BOURDIEU, 1983a; 1983b; 2004).

Nesse sentido, os achados expostos na Tabela 2, acerca do número de orientadores por temática analisada, corroboram a reflexão teórica sobre a relação de dominação dos agentes no campo científico de Bourdieu (2004).

Tabela 2 - Número absoluto de orientadores de dissertações e teses por PPGEF e enfoque temático no período de 2001 a 2010.

\begin{tabular}{l|c|c|c|c}
\hline $\begin{array}{l}\text { Número de orientador por enfoque } \\
\text { temático/ PPGEF }\end{array}$ & Biodinâmica & Sociocultural & Pedagógica & Total \\
\hline USP & 40 & 6 & 9 & 55 \\
UGF & 9 & 9 & 8 & 26 \\
UNESP & 32 & 16 & 14 & 62 \\
UFRGS & 20 & 15 & 11 & 46 \\
UNICAMP & 31 & 31 & 25 & 87 \\
\hline TOTAL & 132 & 77 & 67 & $\mathbf{2 7 6}$ \\
\hline
\end{tabular}

Fonte: dados originais da pesquisa 
Para interpretação da Tabela 2, faz-se necessário ressaltar que, recorrentemente, orientadores de dissertações e teses classificadas no enfoque sociocultural também figuravam na orientação de alguns trabalhos da temática pedagógica. Nesse sentido, deve-se levar em consideração a impossibilidade de somar orientadores dessas duas subáreas para comparação com o enfoque biodinâmico. Esse fato pode ser explicado pela aproximação de ambos os enfoques com referenciais teóricos das Ciências Humanas e Sociais.

Deste modo, a Tabela 2 revela que há quase o dobro de docentes que orientam trabalhos na vertente biodinâmica, nos PPGEF investigados, se comparados aos do viés sociocultural e pedagógico. A temática sociocultural aparece em segundo lugar, expressivamente inferior ao enfoque biodinâmico. Novamente, a perspectiva pedagógica é aquela que possui menos orientadores em quase todos os PPGEF - exceto o programa da USP, no qual há três orientadores a mais que na subárea sociocultural, mas 31 orientadores a menos que no enfoque biodinâmico.

Rigo, Ribeiro e Hallal (2012), ao analisarem a constituição de todos os PPGEF ativos na época da realização da investigação, com base nos documentos fornecidos pela Capes, obtiveram achados similares. Dentre outros aspectos, o número de pesquisadores que realizavam seus estudos no enfoque temático biodinâmico constituía quase o dobro de docentes atrelados aos enfoques pedagógico e sociocultural. Além disso, observava-se que programas detentores de conceitos mais altos na avaliação da Capes possuíam foco na subárea biodinâmica.

Sendo assim, é possível presumir que a hegemonia biodinâmica no campo da Educação Física está longe de inclinações "naturais" que guiam os pesquisadores por um interesse "hagiográfico", isto é, puro e desinteressado, conforme é possível presumir a partir de Tani (2000), Amadio (2003) e Kokubun (2003). É, portanto, resultado da ação de agentes dominantes e "estruturas estruturantes" que moldam o campo científico da Educação Física de acordo com seu interesse, ou neste caso, com a conservação e reprodução de suas regras (MARCHLEWSKI; MAIA DA SILVA; SORIANO, 2011; MAIA DA SILVA; SORIANO, 2014).

No que tange às orientações pedagógica e sociocultural, Betti (2005), fazendo valer a construção identitária proposta por Valter Bracht, expõe o caráter fundamental da Educação Física enquanto uma prática pedagógica, voltada para a intervenção social. Ora, se o locus principal de produção científica, a pós-graduação, apresenta números substancialmente inferiores na relação entre o enfoque temático biodinâmico e os sociocultural e pedagógico principalmente quanto a este último -, é razoável afirmar que a área estaria se configurando em outro formato, ao menos diferente daquele proposto por esses autores.

A dissonância encontrada ultrapassa a dicotomia entre a proposta teórica sobre a Educação Física e o que de fato se produz na área: há, também, um descompasso com as políticas públicas educacionais para a pós-graduação no país. De acordo com o Fórum de Pesquisadores das Subáreas Sociocultural e Pedagógica (CENÁRIOS..., 2015), as orientações do Sistema Nacional de Pós-Graduação (SNPG), que preconizam o aumento da formação e pesquisa de recursos humanos para atuação em licenciaturas, e conforme as premissas da produção científica na temática pedagógica, que deveriam essencialmente fornecer subsídios teóricos para a formação inicial e continuada na licenciatura da área, observa-se nítida discrepância entre a produção cientíica analisada na Educação Física e as diretrizes propostas. 
De modo a ilustrar a análise aqui empreendida, ao considerar o campo científico da Educação Física como campo de disputas, influenciado por diferentes referenciais teóricos e agentes que visam sua conservação ou transformação, cabe resgatar um dos episódios entre esses agentes. Kokubun $(2003,2004)$, à época presidente da comissão de avaliação da Área 21 da Capes, argumentou no sentido de conservar as estruturas que regiam a produção científica da área, utilizando-se da concepção de ciência vinculada às Ciências Naturais na Educação Física.

Já Betti et al. (2004) manifestaram insatisfação com a política científica de avaliação da Capes para a Educação Física. Os autores ressaltaram que, mediante a pluralidade de conhecimentos presentes na área, as normas de avaliação estariam privilegiando as pesquisas e investigações daqueles que produzem no enfoque temático biodinâmico, enquanto dificultariam as investigações na perspectiva sociocultural e pedagógica.

Um indício acerca da influência das normas de produção científica da área, efetivamente na orientação temática e metodológica das pesquisas, é evidenciado no conceito conferido a cada programa nas avaliações da Capes referentes aos períodos: 2003, 2006, 2007-2009, 2010-2012 ${ }^{12}$. Neste recorte, os PPGEF USP e UNESP sustentaram-se com conceitos altos, apresentando na última avaliação trienal os conceitos mais elevados da área, respectivamente: 7 e 6.0 programa da UFRGS manteve o conceito 5 em todo o período. Já o programa da UNICAMP, que em 2003 pontuava o conceito 5 , nos períodos seguintes desceu e estagnou no conceito 4.

O programa da UGF merece atenção especial: em 2003 é classificado com o conceito 5, passa para 4 na avaliação 2007-2009 e não apresenta resultado na última avaliação, pois foi desativado devido ao fechamento da universidade. Ante o exposto, é notória a associação entre os conceitos mais altos e os PPGEF que produzem majoritariamente no viés biológico da área, enquanto aqueles atrelados às temáticas sociocultural e pedagógica estão em descenso.

Quanto à perspectiva dos anos posteriores ao do recorte temporal deste estudo, como descrito pelo Fórum de Pesquisadores das Subáreas Sociocultural e Pedagógica (CENÁRIOS..., 2015), no triênio 2010-2012, o número de dissertações e teses com enfoque pedagógico diminuiu ainda mais. Um agravante desse cenário é o fechamento da UGF e, consequentemente, do PPGEF dessa universidade. A projeção realizada, ao subtrairmos toda a produção realizada por este PPGEF, no âmbito das Ciências Humanas e Sociais, do cenário da produção científica da Educação Física brasileira, denota uma supremacia ainda mais contundente de estudos com enfoque temático biodinâmico na área ${ }^{13}$.

Nesse sentido, a saída para aqueles que realizam pesquisas no enfoque temático sociocultural e pedagógico na Educação Física, apontada por Lovisolo (2014), parece cada vez mais uma realidade latente: a "fuga" para outros campos que possuam uma política de produção científica adequada ao tipo de pesquisa característico das Ciências Humanas e Sociais - como o campo da Educação, História e Ciências Sociais.

\section{CONSIDERAÇÕES FINAIS}

Para além da construção final do fato científico, de sua "verdade última", buscou-se neste estudo investigar alguns dos aspectos que permeiam a constituição do campo científico

12 As planilhas comparativas e avaliações trienais estão disponíveis em: <http://www.capes.gov.br/avaliacao/sobre-a-avaliacao>.

13 É necessário resaltar que além da Educação Física, a Área 21 é composta também pela Fonoaudiologia, Fisioterapia e Terapia Ocupacional. Assim, amplia-se a supremacia das Ciências Biológicas, além de referendar um modus operandi típico das Ciências Naturais e Biológicas para a Área 21. 
da Educação Física no sentido de apreender determinadas relações forjadas na pós-graduação stricto sensu brasileira.

O estudo revelou a polarização temática no campo, a qual se constitui, em números absolutos, predominantemente de dissertações e teses cujo enfoque temático é o biodinâmico e que se concentram em especial nos PPGEF da USP, UNESP e UFRGS. Por outro lado, as temáticas sociocultural e pedagógica podem ser observadas nas dissertações e teses defendidas nos PPGEF UGF e UNICAMP. Achado a ser ressaltado, a vertente pedagógica característica fundamental da Educação Física - foi encontrada em menor proporção em todos os PPGEF investigados.

O número de orientadores das dissertações e teses investigadas, divididos pelos enfoques temáticos categorizados, corroboraram os achados supracitados. Observa-se a predominância - quase o dobro - de docentes que orientaram trabalhos com enfoque temático biodinâmico, se comparados aos que acompanharam estudos socioculturais ou pedagógicos. Ressalte-se que este último, novamente, apareceu em menor proporção em relação aos demais.

Neste contexto, o presente estudo constituiu argumento robusto ao convergir com 0 que uma ampla gama de autores tem discutido no campo: a influência de regras de avaliação da Capes ao conformar o campo científico da Educação Física.

O cenário atual parece ser mais agravante. Posta a dependência que pesquisadores vinculados às Ciências Humanas e Sociais, na Educação Física, possuem de determinados PPGEF, como observado nos dados apresentados, a desativação da UGF sugere prevalência ainda maior de estudos com enfoque temático biodinâmico, relegando apenas ao PPGEF UNICAMP produção mais expressiva quanto aos enfoques temáticos sociocultural e pedagógico.

Assim, recomenda-se o fomento de mais estudos desta natureza, no sentido de aprofundar esta discussão que influenciará diretamente no desenvolvimento da constituição epistemológica da área.

\section{REFERÊNCIAS}

AMADIO, Alberto Carlos. Trajetória da pós-graduação stricto sensu na Escola de Educação Física e Esportes da Universidade de São Paulo após 25 anos de produção acadêmica. Revista Brasileira de Ciências do Esporte, v. 24, n. 2, p. 25-36, jul. 2003.

BETTI, Mauro. Educação física como prática científica e prática pedagógica: reflexões à luz da filosofia da ciência. Revista Brasileira de Educação Física, v. 19, n. 3, p. 183-197, jul./set. 2005.

BETTI, Mauro; CARVALHO, Yara Maria de; DAOLIO, Jocimar; PIRES, Giovani De Lorenzi. A avaliação da educação física em debate: implicações para subárea pedagógica e sociocultural. Revista Brasileira de Pós-Graduação, v. 1, n. 2, p. 183-194, nov. 2004.

BOURDIEU, Pierre. O campo científico. In: ORTIZ, Renato. (org.). Pierre Bourdieu : Sociologia. São Paulo: Ática, 1983a. p. 122-156. (Coleção Grandes Cientistas Sociais).

BOURDIEU, Pierre. Questões de sociologia. Rio de Janeiro: Marco Zero, 1983b. 
BOURDIEU, Pierre. Os usos sociais da ciência: por uma sociologia clínica do campo científico. Tradução Denice Barbara Catani. São Paulo: UNESP, 2004.

DAOLIO, Jocimar. O ser e o tempo da pesquisa sociocultural em Educação Física. Revista Brasileira de Ciências do Esporte, v. 29, n. 1, p. 49-60, jul. 2007.

DACOSTA, Lamartine Pereira; DUARTE, Cátia Pereira. O debate epistemológico da Educação Física no âmbito dos cursos de pós-graduação stricto sensu reinterpretado por contribuições da Teoria da Complexidade de Morin. Revista Brasileira de Ciências do Esporte, v. 24, n. 2, p. 147159, jul. 2003.

CENÁRIOS de um descompasso da pós-graduação em Educação Física e demandas encaminhas à CAPES. In: FÓRUM DOS PESQUISADORES DAS SUBÁREAS SOCIOCULTURAL E PEDAGÓGICA, 2015. Disponível em: <http://www.cbce.org.br/noticiasdetalhe.php?id=1074>. Acesso em: 31 mar. 2016.

JOB, Ivone. Análise bibliométrica das teses de uma comunidade científica em Educação Física com uso do método indiciário. Revista Brasileira de Ciências do Esporte, v. 28, n. 1, p. 201-216, jul. 2008.

KOKUBUN, Eduardo. Pós-graduação em educação física no Brasil: indicadores objetivos dos desafios e das perspectivas. Revista Brasileira de Ciências do Esporte, v. 24, n. 2, p. 9-26, jan. 2003.

KOKUBUN, Eduardo. A avaliação da Educação Física em debate: esclarecimentos. Revista Brasileira de Pós-Graduação, v. 1, n. 2, p. 195-200, nov. 2004.

LAZZAROTTI FILHO, Ari; SILVA, Ana Marcia; NASCIMENTO, Juarez Vieira do; MASCARENHAS, Fernando. Modus operandi da produção científica da Educação Física: uma análise a partir das revistas e suas veiculações. Revista da Educação Física/UEM, v. 23, n. 1, p. 1-14, 10. trim. 2012.

LAZZAROTTI FILHO, Ari; SILVA, Ana Márcia; MASCARENHAS, Fernando. Transformações contemporâneas do campo acadêmico-científico da Educação Física no Brasil: novo habitus, modus operandi e objetos de disputa. Movimento, v. 20, n. esp., p. 67-80, 2014.

LOVISOLO, Hugo. Gestão de revistas: algumas considerações e sugestões para o debate. Revista Brasileira de Ciências do Esporte, v. 36, n. 4, p. 708-714, nov. 2014.

LÜDORF, Sílvia Maria Agatti. Panorama da pesquisa em Educação Física da década de 90: análise dos resumos de dissertações e teses. Revista da Educação Física/UEM, v. 13, n.2, p. 19-25, 2002.

MANOEL, Edilson de Jesus; CARVALHO, Yara Maria. Pós-graduação na educação física brasileira: a atração (fatal) para a biodinâmica. Educação e Pesquisa, v.37, n.2, p. 389-406, maio/ago. 2011.

MAIA DA SILVA, Priscilla; SORIANO, Jeane Barcelos. Qualis periódicos e a produção de capital científico nos programas de pós-graduação em Educação Física. Movimento, v. 20, n. 1, p. 281304, jan/mar. 2014.

MARCHLEWSKI, Camila; MAIA DA SILVA, Priscilla; SORIANO, Jeane Barcelos. A influência do sistema de avaliação Qualis na produção de conhecimento científico: algumas reflexões sobre a Educação Física. Motriz, v.17, n.1, p.104-116, jan./mar. 2011. 
MENDES, Maria Isabel Brandão de Souza; NOBREGA, Terezinha Petrucia da. O Brazil-Medico e as contribuições do pensamento médico-higienista para as bases científicas da educação física brasileira. História, Ciências, Saúde de Manguinhos, v. 15, n. 1, p. 209-219, jan.-mar. 2008.

MOLINA NETO, Vicente et al. Reflexões sobre a produção do conhecimento em educação física e ciências do esporte. Revista Brasileira de Ciências do Esporte, v. 28, n. 1, p. 145-165, set. 2006.

RESENDE, Helder Guerra de; VOTRE, Sebastião Josué. O programa de pós-graduação stricto sensu da Universidade Gama Filho: características, realizações e desafios. Revista Brasileira de Ciências do Esporte, v. 24, n. 2, p. 49-73, jul. 2003.

RIGO, Luis Carlos; RIBEIRO, Gabriela M.; HALLAL, Pedro C. Unidade na diversidade: desafios para a Educação Física do Século XXI. Revista Brasileira de Atividade Física \& Saúde, v. 16, n. 4, p. 339-345, 2012

ROSA, Suely; LETA, Jacqueline. Tendências atuais da pesquisa brasileira em Educação Física Parte 2: a heterogeneidade epistemológica nos programas de pós-graduação. Revista Brasileira de Educação Física e Esportes, v.25, n.1, p.7-18, jan./mar. 2011.

SÁNCHEZ GAMBOA, Sílvio. Epistemologia da educação física: as inter-relações necessárias. Maceió: EDUFAL, 2007.

SOARES, Carmem. Do corpo, da Educação Física e das muitas histórias. Movimento, v.9, n.3, p. 125-147, set./dez. 2003.

SOUZA E SILVA, Rossana Valéria. Mestrados em Educação Física no Brasil: Pesquisando suas pesquisas. 1990. 109 f. Dissertação (Mestrado) - Universidade Federal de Santa Maria, Santa Maria, 1990.

SOUZA E SILVA, Rossana Valéria. Pesquisa em Educação Física: determinações e implicações epistemológicas. 1997. 279f. Tese (Doutorado) - Unicamp, Campinas, 1997.

TANI, Go. Os desafios da pós-graduação em Educação Física. Revista Brasileira de Ciências do Esporte, v.22, n.1, p. 79-90, set.2000.

TURATO, Egberto Ribeiro. Tratado da metodologia da pesquisa clínico-qualitativa: construção teórico-epistemológica, discussão comparada e aplicação nas áreas da saúde e humanas. 2.ed. Petrópolis, RJ: Vozes, 2003.

VELOZO, Emerson Luís. Educação física, ciência e cultura. Revista Brasileira de Ciências do Esporte, v. 31, p. 79-93, 2010. 
Apoio:

CNPQ 